\title{
APROXIMAGION AL DELITO ENTRE LOS INCAS
}

\author{
Franklin Pease G. Y.
}

Para un sistema jurídico como el europeo, el delito es la infracción de una disposición legal, generalmente escrita y publicada, es la contradicción a un mandato de la sociedad efectuado a través de sus órganos legislativos. De esta manera el derecho se entiende identificado con una legislación positiva, y el hombre de hoy - no especialista- no establece una distinción muy clara entre ésta y el Derecho. El hombre de las sociedades arcaicas se encuentra en una situación diferente desde el momento en que el delito viene a ser en última instancia la ruptura de un orden cósmico, sagrado e inmutable, y no sólo la de un ordenamiento legal cambiante. El castigo es una reparación, no de un derecho individual -o estatal - violentado, sino del ordenamiento del mundo, de cuya estabilidad depende su supervivencia. La religión preside el mundo jurídico de los pueblos arcaicos, y así no debe extrañar que muchas veces la norma legal se encuentre asumida por otra religiosa.

Antes de analizar aquellos delitos que las crónicas de los siglos XVI y XVII han conservado, es necesario precisar que muchas de las "normas" detalladas por estos autores parecen estar incluídas entre las prohibiciones llamadas tabú. En principio, tabú significa prohibición, pero esta prohibición funciona dentro de la ambivalencia de lo sagrado; ya hace muchos años indicaba Freud que el tabú presenta "dos significaciones opuestas: la de lo sagrado o consagrado y la de lo inquietante, peligroso, prohibido e impuro. En polinesio, lo contrario a tabú es noa, o sea lo ordinario, lo que es accesible a todo el mundo. El concepto de tabú entraña, pues, una idea de reserva $y$, en efecto, el tabú se manifiesta esencialmente en prohibiciones $y$ restricciones. Nuestra expresión "temor sagrado" presentaría en muchas ocasiones un sentido coincidente con el de "tabú" (1). Notamos que el tabú se presenta como participando no sólo de lo sagrado, sino también de su carácter de "tremendo", para usar la expresión de R. Otto (2). El tabú entraña así un poder fundamental que escapa a todo control humano (3), y este poder origina la prohibición, como una relación entre el hombre y lo sagrado, relación dependiente desde que la violación del tabú ocasiona la reac. ción automática del poder en forma de un castigo - sanción terrible, no siempre determinado. El tabú se relaciona así con algo más que un delito y su sanción legal. La reacción contra la violación del tabú no tiene el carácter ya definido de "sanción", sino que se trata de una violenta reacción del poder de lo sagrado; "No necesita imponerse castigo cuando el poder se precipita sobre uno por sí mismo" (4). Se explicará mejor esta cuestión si se recuerda el castigo a los criminales políticos romanos, que eran arrojados de la roca Tarpeya (Saxum Tarpeyum); no se trata realmente de un "castigo", sino de una reacción del poder. Los tribuni plebis eran funcionarios sacros desde que eran portadores de una potencia absolutamente violenta, y se presentaban como "ejecutores" de este poder. Aquel que caía de la roca Tarpeya sin morir a consecuencia de las lesiones, salvaba la vida, de modo que el hecho aparecía más como una manifestación casual del poder, como un accidente, que no como una ejecución (5). Este caso indica como en Roma se representaba el castigo por la violación de un tabú, impuesto por la divinidad "poderosa", que resguarda al estado por

(1) Freud, 1967, 29-30.

(2) Otto, 1965, 26, y passim.

(3) Van der Leeuw, 1964, 34, 35; Brunner, 1963, 328.

(4) Brunner, loc. cit.

(5) Van der Leeuw, 1964. 37. 
medio del tabú inicial, transformado posteriormente en leyes de protección que sancionan a quienes atentan contra el estado o sus representantes. El tabú se ve así identificado inicialmente con lo sagrado, conservado en normas consuetudinarias, y $\mathrm{fi}$ nalmente asimilado al derecho. El tabú no tiene a priori una cualidad jurídica, así como tampoco la tiene religiosa, sino que recibe estas cualidades de la materia de que trata. Por lo mismo, puede afirmarse que nada importa si la violación del tabú ha sido intencionada o voluntaria, no hay atenuantes ni agravantes, desde que el hecho fundamental es la ruptura del orden.

El tabú lo encontramos vinculado al derecho, ya no sólo en el orden general de "lo prohibido", sino en su vinculación con la propiedad (o posesión), por ejemplo. En Indonesia y Polinesia, una marca indica la prohibición de robar los frutos de un terreno o de cruzar por el mismo, sin violar el tabú (6). Los cro. nistas relatan cómo los naturales del país de los incas no utilizaban puertas aseguradas para proteger sus habitaciones, sino que bastaba poner en ellas un palo atravesado para indicar que el dueño de casa había salido; este hecho puede asimilarse claramente a un tabú y no a disposiciones legales concretas. "Un determinado tabú, el manojo de hojas atado a una pértiga, representa, con su garantía de fuerza sobrenatural el medio corriente de proteger a la propiedad entre los primitivos de Oceanía..." (7). De modo semejante puede interpretarse el dicho del cronista, y así será posible ver un claro origen sagrado a muchas de las disposiciones legales que las crónicas conservan.

El conocido saludo de los incas, l"ama sua, ama llulla, ama quella..." l, que la mayoría de los cronistas ha considerado, ha sido interpretado como una fórmula de salutación, de resumen y propaganda legal (8). Esto merece ser completado. El problema originario parte del tabú, pues para el hombre arcaico el extranjero (y también el soberanol son tabú. El rey lo es por ser poderoso (portador de poder) pero éste es tema aparte; el extraniero lleva consigo un poder desconocido, también as tabú. "Por eso el saludo es un acto religioso que capta el primer em-

(6) Van der Leeuw, 1964. 40, 41.

(7) Firth, 1964. 159.

(8) Valcårcel, 1967, 129. bate del poder $y$ al que se agrega el nombre divino o se le imputa un poder apaciguador (la salutación de paz semítica, adieu, Grüssgott" (9). EI "adios" tiene la misma calidad que el primitivo "shalom" israelí, o el "salve" romano, aunque no tiene idéntico sentido ""Adios" - a Dios te encomiendo-; "Shalom" - la paz sea contigo-. "Salve" -salud para ti-). Considerándola desde este punto de vista, la vieja salutación andina no sólo presenta una imagen pacífica del salutante, sino que al mismo tiempo éste se resguarda del embate de poderes que ambos representan.

La costumbre adquiere igualmente entre los incas un valor fundamental para el estudio del derecho, no solamente por la ausencia de escritura, sino porque lo acostumbrado, lo establecido, es lo recto, lo real, lo verdadero para el hombre tradicional. El comportamiento se refiere siempre a un origen divino, arquetípico, en el que se atribuye a la divinidad el inicio del orden establecido "in illo tempore", es decir en el tiempo sagrado original e indeterminado, en el que se reciben todas las revelaciones primordiales. De modo que tampoco el ordenamiento legal de la sociedad es un proceso consciente. Así no sorprende que algunas sociedades piensen inclusive que su ordenamiento legal ha existido siempre (10). El tiempo sagrado de los Incas es el del Manco Cápac mítico, a quien los cronistas presentan como arquetipo jurídico, que ha dejado hechas todas las leyes, unas puestas en uso, y las otras en proyecto (11). El hecho que Manco Cápac figure como autor originario de todos los textos tiene indudable relación con el procedimiento que siguen los incas del Cuzco estatal, posteriores a Pachacútec, y que llevó a establecer una continuidad que los cronistas sólo pudieron explicar genealógicamente, entre el arquetipo primordial Manco Cápac y los sucesores de Pachacútec. Los crónicas dejan entrever que se establecía una identificación entre Manco Cápac y Pachacútec, considerándolos a ambos como arquetipos fundamentales, fundadores del Cuzco y del mundo (12). Esto explica por qué en el área andina

(9) Van der Leeuw, 1964, 34.

(10) Firth, 1964, 145, 153.

(11) Garcilaso, 1960, I. cap. XV; II cap. IX, 156; Santa Cruz Pachacuti, 1960, 142 ; Cobo, 1964 XI, cap. IV, 66; Cieza, 1945, XXXVIII, 125.

(12) Pease, 1967, 13-15; Manco Cápac es también un arquetipo jurídico. 
las leyes son desde siempre, desde el comienzo del Mundo, y el mundo de los incas comenzó con Manco Cápac, el fundador mítico del Cuzco.

Es natural que la costumbre legal recibida de generación en generación, y ordenada luego en normas jurídicas, no puede separarse de la religión; más aún, la costumbre es esencialmente religiosa (13), también es evidente que "el temor que se afirma se convierte en observancia. Podemos seguir este desarrollo en el concepto romano de religio, que originariamente no significa sino tabú (14). Esta relación perdura posteriormente, aún después de la diferenciación de la norma propiamente dicha. Es claro el caso que los cronistas traen acerca de las relaciones sexuales anormales, cuya realización no estaba permitida al hombre común y que, en ciertas regiones del área andina, se vinculaba ya sea a la élite (que guardaba siempre un carácter religiosol o a la clase sacerdotal (15). "Se tiene ciertamente que en los oráculos y adoratorios donde se daban las respuestas hacía entender (el "demonio", la divinidad - cualquier divinidad-andina, llamada asi por los cronistas) que convenía para el servicio suyo que algunos mozos desde su niñez estuviesen en los templos, para que a tiempo y cuando se hicieran los sarificios y fiestas solemnes, los señores y otros principales usasen con ellos el maldito pecado de la sodomía..." (16). Este no es un caso único de relaciones sexuales anormales, consideradas como una costumbre de carácter religioso, y son conocidos los casos de prostitución sagrada en distintos pueblos. Más adelante nos ocuparemos con mayor extensión de este problema.

"La costumbre -escribe Raymond Firth- es una expresión empleada con exceso y abarca muchas clases de normas. En las sociedades primitivas existen pautas del mismo tipo que las que nosotros catalogamos con nombres tales como educación, ética, moral, ley y religión, si bien nuestras clasificaciones no siempre son efectuadas muy consciente y clara-

(13) Van der Leeuw, 1964, 437.

(14) Van der Leeuw, 1964, 39; Brunner, 1963, 327. 328.

(15) Cieza, 1943, XXV, 144; Toledo, 1920. 115; Garcilaso, 1960, III, cap. VII, 32; Vásquez de Espinoza, 1958, LXXXIV, 532; Valera, 1950. 185; Arriaga, 1920, 35, 36.

(16) Cieza, 1945, LXIV, 191. mente" (17). Así, la costumbre puede ir diferenciándose en distintas costumbres, aplicables a la religión la moral o el derecho. Nos es forzoso reconocer, entonces, la forma cómo debió influir en la elaboración y aún en la forma de aplicar la ley incaica. No sorprende encontrar que al ser preguntado un testigo (cualquier testigo, citado en cualquier cró. nica o visita) sobre la manera de castigar un delito, responda aplicando el principio general a un caso concreto, será casi imposible encontrar una fórmula general y abstracta en las crónicas; siempre en estos testimonios encontramos la costumbre jurídica aplicada a un hecho concreto. Las muchas páginas que dedica Guamán Poma a las "ordenanzas" de los incas, son un ejemplo de este tipo de información (18).

Considerando siempre que los delitos eran pensados como una violación de un orden religioso fundamental, podemos intentar una clasificación de los mismos en el país de los incas, identificando en un primer lugar y simultáneamente aquellos que se cometían contra el estado, el culto y la persona del inca; en segundo lugar los que afectan a las personas; en tercer lugar los que se refieren al bien colectivo /desde que no puede hablarse de "propiedad", si puede en cambio pensarse en "derechos" sobre cosas, en "derecho" a recibirlas o usarlas). Finalmente mencionaremos los "delitos" sexuales, considerados así por los cronistas a despecho de lo que pudieran significar en el mundo andino.

\section{a. Delitos contra el estado, el culto y el Inca.}

Ya indicamos las razones por las cuales sólo se encuentra referencias a casos concretos, de los cuales debemos inferir la norma, aun cuando el cronista no lo haya intentado. Por otro lado es de lamentar que la cuestión legal no haya inquietado a los cronistas, salvo excepciones, y especialmente cuando se trata de disposiciones que se refieren a la forma de reparto de bienes, tributación al estado, etc. (19).

El "estado" cuzqueño era considerado hechura divina; no podemos olvidar que fue Manco Cápac, un

(17) Firth, 1964, 146.

(18) Guaman Poma, 1936, 182, 365.

(19) Cfr. las visitas de Chucuito y Huánuco, y obras como las de Polo, Santillán, etc. 
arquetipo fundador primordial, quien organizó inicialmente el Cuzco, según la tradición cuzqueña recogida por las crónicas; posteriormente la figura del primer inca de la capaccuna es repetida por Pachacútec, el nuevo fundador del centro del mundo que era el Cuzco (20). El Cuzco —ciudad sagrada-, y el estado forman así parte de un todo sagrado que es el centro y eje de la cosmovisión. No extrañe entonces que la rebeldía contra el estado fuera severamente castigada, desde que significaba la violación del orden fundamental y sagrado. Garcilaso apunta que se reemplazaba al curaca sublevado, aunque añade que la pena sólo alcanzaría al directamente culpable, y no al presunto sucesor (21). El cronista no indica aquí la pena concreta, y sólo más adelante señala los horrendos castigos que caían ya no solamente sobre el funcionario sublevado, sino sobre quienes lo secundaban, y aún sobre toda la población a él sujeta; Sarmiento, Murúa, Santa Cruz Pachacuti y otros cronistas señalan casos de castigos masivos (22). El Cuzco, el estado y el Inca se encontraban protegidos por tabús que les otorgaban un aislamiento necesario. El aislamiento del Cuzco se puede apreciar en el hecho de que sólo se podía entrar en él bajo la luz del día (23), y esto estaba motivado porque la situación del día es de cosmos, mundo organizado por la divinidad y bajo su protección, mientras que la noche escapa a esta situación. La misma calidad de centro del mundo, que el Cuzco tenía lo aislaba, desde que hacía necesario cierto ritual para ingresar en él. El ingreso sin cubrir las normas establecidas era ya una ruptura del tabú y exigía una reparación, o mejor, una retribución, que significa en última instancia la reposición del orden violentado. El castigo reviste entonces una situación especial, desde que no es un poder humano el que lo establece, sino divino. No extrañe que se encuentre muchas veces una sanción que, en última instancia, escapa al poder de decisión humano. De la misma forma que cuando se presentaba un caso de sucesión al poder, se preguntaba a las divinidades Ivéase el ritual adivinatorio de la calpa, utilizado en el caso de la sucesión de Guayna Ca-

(20) Pease, 1967, 22. 23; 1968 a., 69, 70.

(21) Garcilaso, 1960, II Cap. XIII, 165.

(22) Sarmiento, 1947, LV, 236; LVII, 238; Murúa, 1962. I, cap XXIX, 72 y ss.; Santa Cruz Pachacut: 1950, 255; Cabello Valboa. 1955, III, cap. XIX, especialmente 347 ; Cieza, 1943 , XL, $203,204$.

(23) Las Casas, 1948, 135. pac (24), se interroga también a la divinidad sobre la inocencia o culpabilidad de los reos, y también se deja en sus manos la decisión final de la ejecución. Guamán Poma explica claramente que ciertos delincuentes eran sometidos a la hiwaya lque en otros testimonios - Relaciones Geográficas de Indias- se llama suwayal, que consistía en dejar caer sobre el reo una galga de piedras, si esta lo dejaba indemne el reo quedaba convertido no solamente en inocente, a juicio de la divinidad, sino en protegido de la misma (25).

La hiwaya deja así en manos de la divinidad el castigo del reo. La adivinación sobre la culpabilidad del reo, que indicamos antes, entraría dentro de la llamada "ordalía", que algunos especialistas asimilan al "iuicio de Dios", tal como se conocía en la edad media europea. La diferencia fundamental es. taría en que los juicios de Dios requerían por lo menos dos contendores, mientras que la ordalía no los necesita. El P. Murúa señala que en una cárcel subterránea ubicada en Sancahuasi, existente cerca del Cuzco, y no en el interior de la ciudad, porque de estar dentro violaría la sacralidad de la misma (de. be pensarse que la costumbre española de ejecutar delincuentes en la plaza mayor debió afectar fuertemente a los indios, desde que violaba el espacio sagrado), había gran cantidad de animales salvajes (felinos, serpientes, alimañas ponzoñosas, etc.) y estaba ". . cubierto y empedrado de piedras muy agudas y esquinadas que cortaban como cuchillos o navajas afiladas...". En ellas arrojaban a quienes atentaban contra el estado o la persona del Inca, y si en el término de un día no eran muertos, los sacaban y reconocían en su honradez, considerados como protegidos de la divinidad (26).

Pero no sólo la rebelión era considerada delito, sino cualquier atentado contra las propiedades que el estado tenía. Era punible entonces el uso indebido de animales estatales, el robo de frutos de la tierra, etc. También lo era el maltrato o destrucción de cualquier tipo de obras públicas; así -habla Cobo- se castigaba la destrucción de las marcas de los caminos y cualquier otro signo de demarcación territorial (27).

(24) Pease, 1968, b., III. 174 y ss.

(25) Guamán Poma, 1936, 188; Cobo. 1964, XII cap. XXVI, 116.

(26) Murúa, 1962, II, cap. VI, 41; Cieza, 1943, XXIV. 138, 139; Guamán Poma, 1936, 303.

(27) Cobo, 1964, XII. cap. XXVI, 117. 
De la misma manera, era considerado delito cualquier cambio local, no ordenado por las autoridades cuzqueñas, que contribuyera a originar algún desorden. Así, se encargaba especialmente que "ninguno fuera osado de ponerse en el traje, insignia de otro; $y$ esto mandaban ejecutar severísimamente" (28).

Si la ley del Inca era divina, igual razón había para divinizar el estado que esta ley organizaba. La violación de la ley, así como la del orden, eran consideradas un sacrilegio. A ello se debía que las leyes no pudieran ser variadas por funcionarios locales (29).

La ruptura del orden legal es equivalente a la violación de un status divino, de manera que puede entenderse que provoca una inmediata necesidad de reparación, cuyos alcances son fijados, en última instancia, por la divinidad.

La persona sagrada del Inca era naturalmente protegida por disposiciones concretas. No sólo debe hablarse aquí de un tabú real, sino que se menciona disposiciones concretas que castigan cualquier atentado contra su persona. El soberano era considerado portador de un poder extraordinario (el Inca es en realidad un dios), en directa vinculación con la divinidad oficial y solar del Tawantinsuyo. El Inca es un reservorio de fuerzas dado que el Inca tiene un poder superior (divino) capaz de ser "terrible" (30).

De modo que no es posible acercarse a él sin tomar ciertas precauciones de protección. Pero en un régimen estatal organizado, no es raro que se agregara al tabú inicial, un instrumento legal que proporcionara una nueva protección. No sólo se amparaba la persona del gobernante, sino aquellas disposiciones que emanan de él (31).

A veces se encuentra en las crónicas disposiciones con claro sabor español, como la que anota el $P$. Valera: "Quien matara al rey, a la reyna o príncipe heredero, muera arrastrado o asotado y sea he-

(28) Vaca de Castro, 1920, 271.

(29) Cobo, 1964. XI. cap. IV, 66; Garcilaso, 1960, II, cap. XIII, 166.

(30) Eliade, 1954, 29

(31) Garcilaso, 1960. IV, cap. XXI, Valcárcel, $1967,129$. cho cuartos, y su casa derrumbada y hecha muladar; sus hijos sean perpetuamente bajos, de vil condición y no pueden tener cargo ninguno honroso en el pueblo ni en la guerra, y todo esto hasta la cuarta generación, y lo mismo los traidores, mas si estos antes de darse la batalla, se arrepintiesen y pidiesen perdón y se metiesen debajo del estandarte del inga, vuelva en su gracia y no padezca nada de lo dicho (32).

En este texto encontramos evidentes elementos europeos, tales como el derrumbar la casa y convertirla en muladar (léase: sembrarla de sall, castigar a los descendientes hasta la cuarta generación, siguiendo las Escrituras, y también los conceptos de honor y servicio a la bandera. Así, muchos ejemplos de las crónicas.

\section{b. Delitos contra la persona.}

Encontramos en las crónicas información sobre castigos a quienes atentaban contra la vida y la salud de las personas, aunque no podemos descubrir en los textos un orden sistematizado (que no sea español), ni una jerarquía de estos delitos. La calificación fundamental está dada por la situación social del ofendido, si era persona sagrada (Inca), miembro de la élite, funcionario o campesino, aún tenía vínculo matrimonial con el acusado, aunque esto presenta problemas relacionados de ejemplos europeos (33).

Comc sucede en muchos pueblos arcaicos, se entendía que la muerte podía ser producida por hechizo, excitación de las fuerzas mágicas contra el agraviado. El daño, la muerte, son causados fundamentalmente por la intromisión de una fuerza sobrenatural, de alli que no se encuentre muchas veces causas físicas a enfermedades o muertes. Por ello se explicaría las penas severas que indica alguna crónica para aquellos que utilizaban los hechizos (34).

La protección a la persona se entiende como ejercitación del tabú personal (recordar lo indicado antes acerca del saludo). La protección funciona aún en caso de castigos indebidos realizados por un funcionario, siempre es precisa la reparación.

(32) Valera, 1960, 184.

(33) Ibidem, 186.

(34) Cobo, 1964, XII, cap. XXVI, 116; XIII, cap. XXV, 228. 


\section{c. Delitos que afectan a los bienes (al bien colec- tivo).}

La situación privilegiada de la élite incaica se aprecia en la presencia de ciertos bienes, y su utilización por ella. Si bien puede aceptarse la utilización de bienes por los hombres de la élite, cuzqueña y local (administrativa), no puede hablarse con mucha seguridad de la tenencia de tierras. Si bien es verdad que las crónicas y muchos documentos posteriores a la invasión europea hacen mención de "tierras de los curacas", "de la nobleza", "del Inca" - "del sol", el problema reside en la forma de entender estos asertos de los cronistas, para lo cual debemos considerar su procedencia europea. De la misma forma que estos autores no pudieron desligarse del concepto europeo de medir la tierra y afirmaron así que el tupu andino era una medida de superficie, extendieron al área andina su propia imagen de propiedad (o posesión de la tierra). El tupu no es medida de superficie, y eso lo prueba la multiplicidad de medidas aplicables a tupus en diferentes lugares, recogidas por los mismos cronistas. Alguna vez se pensó en resolver el problema, pensando que las diferencias de medidas se debían a las variedades de tierras utilizadas en distintos lugares y desigual fertilidad de las mismas; inclusive se ha propuesto un "promedio" de las diversas medidas aplicables a tupu en el área andina (35).

Es preciso indicar, que si aceptamos de hecho diferentes "medidas" para los tupus, no podemos hablar de unidad de medida, por naturaleza única, tampoco podemos aceptar un promedio de medidas como patrón. Por otro lado, tanto las crónicas como los documentos regionales nos precisan que funcionaba un régimen colectivo de trabajo, lo cual no sólo indica la participación de toda la comunidad del ayllu, sino que esta participación es simultánea; de esta manera no es preciso parcelar las tierras y la relación tupu-parcela se presenta como demasiado débil. Finalmente, la existencia de tupus de agua, de chicha, etc., terminan de aclarar la cuestión, puesto que es imposible concebir "superficies de agua". Lo que el tupu fue, en realidad, es una medida cúbica, de capacidad, y las crónicas lo indican al precisar que el tupu proporcionaba anualmente al hombre una cantidad de alimentos para

(35) Valcárcel, 1967, 101. subsistir durante un año; concibiéndolo así se explica además la existencia de tupus para medir líquidos. Se encuentra clara, además, la relación tupu-fanega, que es una medida cúbica, sólo ocasionalmente aplicable a superficie en la España del XVI. (36).

El uso de las tierras era colectivo en los ayllus, y sólo encontramos rastros de utilización por limitados grupos entre los Lupaca de Chucuito, visitados por Garcí Díez de San Miguel en 1564, y por Pedro Gutiérrez Flores en 1571-2.

Allí se aprecia la propiedad de ganado por familias extendidas, lo que ocasionaba que sólo en Chucuito puede apreciarse "ricos" y "pobres" en una misma etnía. Así se encuentra una importante distinción entre las áreas predominantemente agrícolas y esta región ganadera; mientras en las primeras hay un reparto igualitario de los bienes, en la última existen bienes a disposición exclusiva de familias propietarias (37).

Si bien el uso de los bienes agrarios quedaba en manos de los ayllus y del estado, que utilizaba la energía humana proporcionada por los primeros, no puede decirse que la tierra haya sido "del estado", "del ayllu", sino que en toda instancia estos son usuarios de la misma. En realidad, la tierra es divina, y son las divinidades quienes otorgan el permiso para trabajarla; esto explica el ritual anual del inicio de la siembra (en general, de todas las labores agrarias) por el Inca en el Cuzco, donde al renovarse el ritual de fundación de la ciudad, el sol vol. vía a fecundar la tierra (38).

Es preciso tener en cuenta que el concepto de propiedad no era igual en el área andina y en la Europa del siglo XVI, por ello el cronista en general tropieza con dificultades al informar sobre la forma de utilizar y distribuir la tierra entre los incas. Para el hombre "primitivo", la propiedad no es una mera relación entre cosa y dueño, que se traduzca en el ejercicio de los derechos que la legislación contemporánea considera, sino que ella llega a significar una relación mística entre la cosa

(36) Murra, 1964 a., 432; Garcilaso, 1960. V, cap. III, 152.

(37) Murra, 1964 b., 80 y ss.

(38) Pease, 1970. 
y el hombre que la usa, "el propietario no es el beafum possidens, sino el detentador de un poder que es superior a él (39).

Se entabla entonces una doble vía de relación, una entre el "propietario" y la cosa, y otra entre el mismo y la divinidad que le otorga el derecho de funcionar como tal. En el caso de la "propiedad" de la tierra en el área andina las cosas funcionan de la misma manera antes dicha. Es cierto, sin embargo, que la información de las crónicas es demasiado débil y refleja siempre los criterios jurídicos europeos, y así los cronistas se limitaron a constituir en propietarios de las tierras a los habitantes andinos, sin considerar algunas veces los aspectos comunitarios del trabajo de las mismas.

Es difícil pensar hoy día, hasta qué punto se puede hablar de una "propiedad" colectiva, que los tratadistas han mencionado a menudo (40), desde el momento en que podemos ver cómo aún hoy día la divinidad dispone de los bienes del suelo. El wamani, divinidad ctónica extendida en el área andina, es quien provee el agua y los frutos de la tierra; dentro de ésta, el amaru es el guardián de las riquezas del subsuelo y el culto que se rinde a estas divinidades está atestiguado hasta el presente: "Todas las montañas tienen Wamani // El Wamani de los pastos para nuestros animales, y para nosotros su vena, el agua... (41); también se le vincula a la mujer, lo que establecería una relación con la tierra, esencialmente femenina (42).

'El _el Wamani- es la tierra, como si fuera Dios, el ser de nuestros animales. Todo viene de él. De él brota la bendición de Dios, la vena, el agua, vena de Dios" (43); "Es el segundo Dios. El que nos cuida, el que nos da de comer" (44).

Por otro lado, encontramos que si bien las primeras tierras que se cultivaban eran las del ayllu,

(39) Van der Leeuw, 1964, 41.

(40) Basadre, 1937, 95 y ss.; Cunow, 1933, 37 y ss.; Baudin, 1955, 142; 1962, 266 -aquí Baudin habla de propiedad "estatal"_-; Valcárcel, 1967, 104 y ss.

(41) Arguedas, 1964, 229 (versión de Viviano Wamancha. indio de Puquio).

(42) Fuenzalida, 1965, 123.

(4.2) A rguedas, 1964, 235.

(44) Ibidem; Mendizábal, 1966; Favre, 1967. sólo el sobrante era usado por el estado incaico y el culto, trabajándolo con el excedente de energía de los ayllus; las panacas cuzqueñas utilizaban permanentemente grandes extensiones de tierras que las crónicas y los documentos del XVI consideran insistentemente como "propiedad" de esos grupos de parentesco de la élite cuzqueña (45). Pero a pesar de la abundancia de información posterior a la invasión europea, siempre ofrece reparos la rápida aculturación de la élite del Tawantinsuyu, y su probado interés en utilizar las ventajas que podía ofrecerle la nueva dominación.

Las dificultades enunciadas anteriormente no impiden apreciar en las crónicas disposiciones que protegen bienes (naturalmente muebles), y así hay referencias a robos comunes, desviación de aguas de regadio, mala administración de funcionarios, del estado o de las comunidades a él sujetas etc. (46).

\section{d. Delitos sexuales.}

Ya hemos mencionado los problemas que trajo la visión europea de los cronistas en cuanto a los de. litos sexuales. Lo sexual funcionaba para ellos vinculado a categorías éticas cristianas, y por ello ca. lificaron como delitos muchas situaciones rituales. Por ello, aunque las crónicas nos hablen de una variedad de estos delitos, desde la sodomía al adulterio, pasando por la prostitución y la violación, tenemos que considerar los diferentes conceptos que se nos plantean cuando tratamos de una cultura absolutamente diferente a la europea, y cuyo concepto de moral sexual era completamente distinto. Un problema que hay que destacar especialmente es la confusión que el cronista hace entre sexo y pecado. La asociación entre estos dos elementos es propia del cristianismo, aunque ha ido variando con el tiempo; lo cual no quita la existencia de tabú sexuales extendidos en el área andina, como en todo pueblo arcaico, lel incesto, por ejemplol, aunque las circunstancias son diferentes a las europeas. Es conveniente considerar, por ejemplo, que la poligamia (matrimonio de un varón con varias mujeres) se explica porque es tabú mantener relaciones con una

(45) Rostworowski, $1962 ; 1964 ; 1966$.

(46) Murúa, 1962. II, cap. VI. 42; II, cap. XXVI, 89: Cieza, 1945, LX. 183; Cobo, XII, cap. XXVI, 117; Guamán Poma, 312 á 328. 
mujer en gestación. Se ha pensado que en el área -andina la poligamia de la élite estaría justificadaademás por la mayor posibilidad de obtener tierras (en realidad frutos) (47), y en todo caso está relacionada con el poder detentado por los grupos dirigentes.

La sodomía aparece claramente identificada en las informaciones de las crónicas, aparte de la cerámica alusiva (48). Sin embargo, los cronistas no pudieron explicarse el carácter sagrado que muchas veces toma este tipo de relaciones; Cieza aporta datos especialmente útiles y referentes a relaciones $\mathrm{ri}$ tuales (49); otras informaciones completan el cuadro, aunque no siempre con la precisión requerida. (50).

Sin embargo, volvemos a recalcar las características especiales de la sodomía en el área andina, y que escaparon a la visión consciente de los cronistas. En primer lugar tuvo sentido sagrado, no es un delito como lo creyeron estos autores, sino que se encuentra casi exclusivamente en los santuarios locales, donde funciona dentro de complicados rituales, como atestigua Cieza (51), y como lo revela la cantidad de ceramios alusivos hallados especialmente en tumbas sacerdotales y en los recintos de los templos. Es natural que los cronistas considerasen pecado y luego delito a la sodomía, pues la Biblia, tanto en el antiguo como en el nuevo Testamento, ha condenado severamente la fornicación masculina aún la realizada bajo pretextos religiosos (52). En Armenia se encuentran rastros de prostitución sagrada (y hieródulos-as) en los templos de la diosa Amaitía; hay casos sumamente conocidos en el resto de la región del Mediterráneo.

La prostitución sagrada ha estado muy extendida en los pueblos arcaicos. Debia apartarse el peligro

(47) Valcárcel, 1967, 206.

(48) Larco Hoyle, 1965.

(49) Cieza, 1945, LXIV. 191.

(50) Toledo, 1920, 116; Valera, 1950, 185; Vázquez de Espinoza, 1958. LXXXIV, 532.

(51) Cieza, 1945, LXIV, 191.

(52) Puede encontrarse ejemplos muy claros en Números, XXV, 1; Deuteronomio, XXIII. 18, 19; Oseas, IV, 13, 14; III Reyes. XIV, i2 y ss.; IV Reves, XXIII, 7; Apocalipsis, XXII, 15 ; y podríamos hallar fácilmente más ejem. plos en toda el área del mar Mediterráneo. de la primera cohabitación entre hombre y mujer, para lo cual se realizaba una ruptura hymenis, que al mismo tiempo garantizaba la eficacia del poder sexual. Quien lo realizaba debía ser generalmente un poderoso. En el sentido de poseedor de un poder sagrado. Este es el camino que lleva fácilmente a la prostitución sagrada (53). Pero también puede realizarse una relación simbólica (dormir con un niño), o mediante la cohabitación con un sacerdote que inicia así a la mujer. La Biblia ofrece ejemplos de prostitución en templos $y$, en cuanto al país de los incas, algunos cronistas señalan que algunos grupos de mujeres que comerciaban con su cuerpo eran marginadas, $y$ otras llegan a condenarlas a muerte, no habiendo mucha más información (54). Sin embargo, volvemos a insistir en nuestro parecer de ser estas imágenes provenientes de la época y cultura españolas, y de la identificación sexo-pecado (lvego sexo-delito, sancionado por la ley), que trajeron los invasores dentro de la concepción cristiana del mundo, y la moral correspondiente.

Aparte es el problema relacionado con puntos como el aborto y el adulterio. Sobre lo primero hay pocas disposiciones en crónicas, y generalmente se relacionan con ingestión de yerbas $y$ otros procedimientos abortivos, ya sea mecánicos o atribuibles a magia; las crónicas indican que la responsabilidad abarcaba por igual a todo tipo de culpables (55). Por otro lado, el concepto actual de adulterio radi. ca en la existencia de un vínculo matrimonial legal (y religioso) que origina un status, cuya violación tipifica el delito. Para el caso de los incas, la existencia de matrimonios diversos (servinacuy, por ejemplol, complican el panorama. El problema parece radicar en el prestigio que confiere la virginidad femenina en el mundo europeo y que no existía en el área andina, "Nunca conocieron el resplandor y hermosura de la castidad -escribe el P. Cobo- para hacer estima della; antes les era muy ofensiva la virginidad en sus mujeres, porque decían que las que estaban doncellas no habian sido queridas por nadie" (56). Frente a esta afirmación de

(53) Van der Leeuw, 1964, 221.

(54) Samuel, II. 22; Oseas, IV, 14; Exodo, XXXVIII, 7; Garcilaso. 1960, IV, Cap. XIV; Cobo, III, Cap. XXXVII, 232; Murúa, 1962, II, cap. XXIl, 90; Basadre, 1937, 168.

(55) Cobo, XII. cap. XXVI, 116; Valera, 1950, 183.

(56) Cobe, XI, cap. VII, 22. 
un cronista observador y cuidadoso, resulta casi ocioso comentar las referencias de otros autores que no llegaron a comprender la situación diferente de los hombres andinos, que funcionaban dentro de un marco cultural muy distinto al europeo, autores como Arriaga y Acosta corroboran las palabras de Cobo (57), y su testimonio parece mucho más seguro que los de Murúa, Valera, Las Casas, Herrera, Garcilaso, etc. (58). No es posible entender hoy al pie de la letra las afirmaciones de estos últimos cronistas que identificaban la institución matrimonial andina con la europea.

Eran diferentes de la misma manera que lo era el concepto de paternidad; los habitantes del Tawantinsuyu no identificaban las relaciones sexuales con la fecundidad de la mujer, sino que, como otros pueblos arcaicos, pensaban que ésta quedaba embarazada por haber entrado en contacto con el subsuelo (donde vivían las fuerzas de la fertilidad); estos puntos de contacto son cavernas, manantiales, barrancos, y cualquier sitio que indique una vía posible de entrada al Ucu pacha o Urin pacha (59).

Todo este material merece sin duda un análisis más cuidadoso que el intentado en estas páginas; es preciso sin embargo, insistir finalmente en la di. ficultad permanente de distinguir lo incorporado por el cronista europeo, de la concepción legal andina. Sólo un largo trabajo etnográfico orientado hacia este problema, podrá ayudarnos a aclarar el panorama.
(57) Arriaga, 1920, 50; Acosta, 1954, IV, cap. XVIII, 197.

(58) Murúa, 1962, II, cap. VI, 42; Valera, 1950, 182-184; Las Casas, 1948, 133; Herrera. 1944, Década V, IV, 288; Garcilaso, 1960 cap. XXI, 115
(59) "Antes de conocer las causas fisiológicas de la concepción los hombres han creído que la maternidad era debida a la inserción directa del niño en el vientre de la madre. Que lo inser. tado sea ya un feto (que habría tenido hasta el momento una vida prenatal en grutas, grietas, pozos, árboles, etc.), que sea simplemente un germen, o el "alma del antepasado"... son cuestiones que no tienen interés... Lo importante es la idea de que lo hijos no son engendrado's por el padre, sino, que, en un momento más o menos avanzado de su desarrollo, vienen a ocupar su lugar dentro del claustro materno a consecuencia de un contacto de la mujer con un objeto, o con un animal del medio cósmico circundante". (Eliade, 1954, 236-7). 


\section{Bibliografía}

ACOSTA S. J., José de

1954 Historia natural y moral de las Indias; Biblioteca de Autores Españoles, vol. LXXIII, Ed. Atlas, Madrid.

ARGUEDAS, José María

1964 Puquio. Una cultura en proceso de cambio; En: Ensayos sobre la cultura actual del Perú. Universidad de San Marcos, Lima

ARRIAGA, S. J., Pablo José de

1920 La extirpación de la idolatría en Perú; Colección de Libros y Docs. referentes a la Historia del Perú, Lima.

BASADRE, Jorge

1937 Historia del Derecho Peruano; Lima.

BAUDIN, Louis

1955 El imperios socialista de los incas; ZigZag, Santiago de Chile.

BRUNNER, August

1963 La religión; Herder, Barcelona.

CABELLO VALBOA, Miguel

1955 Miscelánea antártica; Universidad de San Marcos. Lima.

CIEZA DE LEON, Pedro

1943 Del señorío de los incas; Edic. Solar, Buenos Aires.

COBO S. J., Bernabé

1964 Historia del nuevo mundo; Biblioteca de Autores Españoles, vols XCL, XCII, Ed. Atlas, Madrid.

CUNOW, Heinrich

1944 La organización social del imperio de los incas; Miranda, Lima.

DIEZ DE SAN MIGUEL, Garci

1964 Visita a la Provincia de Chucuito... En el año 1567; Casa de la Cultura del Perú, Lima.

ELIADE, Mircea

1954 Tratado de historia de las religiones; Instituto de estudios políticos, Madrid.

FIRTH, Raymond

1964 Tipos humanos; Eudeba, Buenos Aires.
FAVRE, Henri

1967 Tayta Wamani. Le culte des montagnes dans le Centre Sud des Andes Péruviennes; En Etudes Latino_Américaines, III, Universite d'Aix-en-Provence.

FREUD, Sigmund

1967 Totem y tabu; Alianza Editorial, Madrid.

FUENZALIDA, Fernando

1965 Santiago y el Wamani. Aspectos de un culto pagano en Moya: Cuadernos de Antropología, VIII, Universidad de San Marcos.

GARCILASO DE LA VEGA, EI Inca

1960 Primera parte de los Comentarios Reales de los incas; Biblioteca de Autores Es. pañoles, vol. CXXXIII, Madrid.

GUAMAN POMA DE AYALA, Phelipe

1936 Nueua coronica y buen gobierno; Institut d'Ethnologie, París.

HERRERA, Antonio de

1944 Historia general de los hechos de los castellanos en las islas y tierra firme del mar océano; Buenos Aires.

LARCO HOYLE, Rafael

1965 Checan. Essai sur les représentations érotiques du Pérou précolombien. Editions Nagel, Genéve.

LAS CASAS, Fray Bartolomé de

1948 De las antiguas gentes del Perú, Miran. da, Lima.

MENDIZABAL, LOSACK, Emilio

1966 El awquillu entre los descendientes de los Chupachos; En: Cuadernos de investigación I, Universidad Nac. de Huánuco.

MURUA, Fray Martín de

1962 Historia general del Perú... 2 vols. Madrid.

MURRA, John V.

1964 a. Una apreciación etnológica de la visita (de Chucuito); En: DIEZ DE SAN MI. GUEL, Garci, 1964, pp. 421-444.

1964 b. Rebaños y pastores en la economía del Tahuantinsuyo; Revista Peruana de Cultura, 2, Lima.

PEASE G. Y., Franklin

1967 En torno al culto solar incaico; Humani. dades, I, Univ. Católica, Lima.

1968 a. El mito del origen cuzqueño y la creación solar; Amaru, 8, Lima. 
1968 b. Los últimos incas del Cuzco; Boletín del Instituto Riva Agüiero, 6, Lima.

1970 The Andean Creator God; Numen, XVII, Leiden.

ROSTWOROWSKI DE DIEZ CANSECO, María

1962 Nuevos datos sobre tenencia de tierras reales en el incario; Revista del Museo Nacional, XXXI, Lima.

1964 Nuevos aportes para el estudio de la medición de tierras en el virreinato $e$ inca. rio; Rev. del Archivo Nacional del Perú, XVIII, Lima.

SANTA CRUZ PACHACUTI, Juan de

1950 Relación de antigüedades deste reino del Pirú; En: JIMENEZ DE LA ESPADA, Marcos, Tres relaciones de antigüedades peruanas, Guarania, Buenos Aires.

SARMIENTO DE GAMBOA, Pedro

1947 Segunda parte de la historia general llallamada indica; Emecé, Buenos Aires.
VACA DE CASTRO, Cristóbal

1920 Declaración de los quipucamayocs a...; Colecc. de Libros y Docs. referentes a la Hisotria del Perú, Lima.

VALCARCEL, Luis E.

1967 Etnohistoria del Perú antiguo, 3ः ed. UNMSM, Lima.

VALERA, S. J., Blas

1950 Relación de las antiguas costumbres del Perú; En: JIMENEZ DE LA ESPADA, Marcos, Tres relaciones de antigüedades peruanas, Buenos Aires.

VAN DER LEEUW, Gerardus

1964 Fenomenología de la religión, FCE., México.

VAZQUEZ DE ESPINOZA, Antonio

1958 Primera parte del Compendio y Descrip. ción de las Indias Occidentales; Smithsonian Institution, Washington. 